\title{
Effect of dried fruit on postprandial glycemia: a randomized acute-feeding trial
}

Effie Viguiliouk ${ }^{1,2}$, Alexandra L Jenkins ${ }^{1,3}$, Sonia Blanco Mejia ${ }^{1,2}$, John L Sievenpiper ${ }^{1,2,4,5}$ and Cyril W C Kendall ${ }^{1,2,6}$

\begin{abstract}
Background/Objectives: To investigate the effect of dried fruit in modifying postprandial glycemia, we assessed the ability of 4 dried fruits (dates, apricots, raisins, sultanas) to decrease postprandial glycemia through three mechanisms: a glycemic index (Gl) effect, displacement effect, or 'catalytic' fructose effect.

Subjects/Methods: We conducted an acute randomized, multiple-crossover trial in an outpatient setting in 10 healthy adults. Participants received 3 white bread control meals and 12 dried fruit test meals in random order. The test meals included each of 4 dried fruits (dates, apricots, raisins, sultanas) alone (Gl effect), 4 of the dried fruits displacing half the available carbohydrate in white bread (displacement effect), or 4 of the dried fruits providing a small 'catalytic' dose (7.5 g) of fructose added to white bread ('catalytic' fructose effect). The protocol followed the ISO method for the determination of GI (ISO 26642:2010). The primary outcome was mean \pm SEM GI (glucose scale) for ease of comparison across the three mechanisms.
\end{abstract}

Results: Ten healthy participants (7 men, 3 women; mean \pm SD age and BMI: $39 \pm 12$ years and $25 \pm 2 \mathrm{~kg} / \mathrm{m}^{2}$ ) were recruited and completed the trial. All dried fruit had a $\mathrm{Gl}$ below that of white bread $(\mathrm{Gl}=71)$; however, only dried apricots $(G l=42 \pm 5)$, raisins $(G l=55 \pm 5)$, and sultanas ( $51 \pm 4$ ) showed a significant $G l$ effect $(P<0.05)$. When displacing half the available carbohydrate in white bread, all dried fruit lowered the Gl; however, only dried apricots $(G l=57 \pm 5)$ showed a significant displacement effect $(P=0.025)$. None of the dried fruits showed a beneficial 'catalytic' fructose effect.

Conclusions: In conclusion, dried fruits have a lower Gl and reduce the glycemic response of white bread through displacement of half of the available carbohydrate. Longer-term randomized trials are needed to confirm whether dried fruit can contribute to sustainable improvements in glycemic control.

Trial registration: ClinicalTrials.gov identifier, NCT02960373

\section{Introduction}

Dried fruits show promising potential for blood glucose management. Previous trials conducted in individuals with and without diabetes have shown dried fruits (including dates, apricots, raisins, and sultanas) to have a

Correspondence: John L Sievenpiper (john.sievenpiper@utoronto.ca) or Cyril W C Kendall (cyril.kendall@utoronto.ca)

'Toronto 3D Knowledge Synthesis and Clinical Trials Unit, St. Michael's Hospital, Toronto, Canada

${ }^{2}$ Department of Nutritional Sciences, Faculty of Medicine, University of Toronto, Toronto, Canada

Full list of author information is available at the end of the article low $(\leq 55)$ to medium (56-69) glycemic index $(\mathrm{GI})^{1-7}$ and to have beneficial effects on postprandial glucose $\mathrm{e}^{3,6,8-11}$ and insulin ${ }^{3,6,11}$ levels, as well as $\mathrm{HbA}_{1 \mathrm{c}}{ }^{8}$ compared to high GI foods (e.g., crackers, cookies, white bread, glucose solution). However, the effect of combining dried fruits with high GI foods has not been adequately addressed. Current research suggests that combining dried fruits with high GI foods by displacing available carbohydrate may benefit postprandial glycemia in comparison to high GI foods alone. This is supported by acute studies showing that nuts and/or dried fruits combined with high

\section{(c) The Author(s) 2018}

(c) Open Access This article is licensed under a Creative Commons Attribution 4.0 International License, which permits use, sharing, adaptation, distribution and reproduction cc) in any medium or format, as long as you give appropriate credit to the original author(s) and the source, provide a link to the Creative Commons license, and indicate if changes were made. The images or other third party material in this article are included in the article's Creative Commons license, unless indicated otherwise in a credit line to the material. If material is not included in the article's Creative Commons license and your intended use is not permitted by statutory regulation or exceeds the permitted use, you will need to obtain permission directly from the copyright holder. To view a copy of this license, visit http://creativecommons.org/licenses/by/4.0/. 
GI foods can attenuate relative glycemic responses in healthy participants when compared to high GI foods alone ${ }^{7,12,13}$. Dried fruits may also benefit postprandial glycemia by providing small or 'catalytic' doses of fructose $(\leq 10 \mathrm{~g} / \mathrm{meal})$. Fructose, through its metabolite fructose-1$\mathrm{P}$, has shown 'catalytic' effects on hepatic glucose metabolism through the induction of glucokinase activity in hepatocytes ${ }^{14-17}$. Infusion studies in humans have shown that this mechanism relates to a $\sim 3$-fold increase in glycogen synthesis under euglycemic conditions in healthy individuals ${ }^{18}$ and a $\sim 30 \%$ decrease in hepatic glucose output under hyperglycemic conditions in individuals with type 2 diabetes ${ }^{19}$. Clinical translation of these findings have shown 'catalytic' doses of fructose at 7.5 and 10 $\mathrm{g}$ to decrease postprandial glycemic responses to oral glucose or high GI meals (e.g., mashed potatoes) by $\sim 15-30 \%$ in healthy individuals ${ }^{20,21}$ and those with diabetes $^{22}$.

Therefore, to address this knowledge gap, we aimed to: (1) quantify the GI of 4 different types of dried fruit (dates, apricots, raisins, sultanas) (GI effect); (2) to assess the ability of these 4 dried fruits to decrease the postprandial glycemic response to white bread by partially displacing available carbohydrate (displacement effect); and (3) by providing a 'catalytic' dose of fructose ('catalytic' fructose effect).

\section{Subjects and methods Participants}

Participants were recruited from the Glycemic Index Laboratories clinic volunteer roster. Inclusion criteria consisted of men or non-pregnant women aged 18-75 years who were in good health. Individuals with a known history of diabetes, heart disease, liver disease, kidney disease, thyroid disease, HIV, or any other major illnesses that may affect carbohydrate metabolism, or using medications which might either make participation dangerous to the individual or affect the results were excluded.

The study was conducted in accordance with the Declaration of Helsinki and was approved by the Western Institutional Review Board ${ }^{\circledR}$ (protocol number: 971199) which meets all the requirements of the U.S. Food and Drug Administration (FDA), the Department of Health and Human Services (DHHS), the Canadian Health Protection Branch (HPB), Canadian Institutes of Health Research (CIHR) and the European Community Guidelines. All participants provided written informed consent prior to starting the study and received a financial reward for their participation. The study was registered on ClinicalTrials.gov (identifier: NCT02960373).

\section{Study design}

This was an acute randomized, multiple-crossover trial that followed the International Organization for
Standardization (ISO) method for determining GI (ISO 26642:2010). Eligible participants underwent 15 separate study meals on 15 separate occasions, with each participant undergoing up to 3 study meals per week separated by at least one day. Randomization of the sequence of study meals was performed using a computer random number generator by a coordinator blinded to the treatment allocation. On each test day, participants came to the clinic (Glycemic Index Laboratories, Toronto, Canada) in the morning after a 10-14h overnight fast. After being weighed and having two fasting blood samples obtained by finger-prick 5 min apart, the participant then consumed a study meal within $15 \mathrm{~min}$. At the first bite a timer was started and additional blood samples were taken at 15, 30, 45, 60, 90 and 120 min after the start of the study meal. Before and during the test, a blood glucose test record was filled out with the participants initials, ID number, date, body weight, study meal, time they started eating, time it took to eat, time and composition of last meal, and any unusual activities. Participants remained seated quietly during the $2 \mathrm{~h}$ of the test. After completing the test, participants were offered a snack and then allowed to leave.

\section{Study meals}

Each participant underwent a total of 15 separate study meals consisting of 3 white bread control meals and 12 dried fruit test meals (Table 1). The test meals included each of the 4 dried fruits (dates, apricots, raisins, sultanas) alone (GI effect), displacing half the available carbohydrate in white bread (displacement effect), or providing a small 'catalytic' dose $(7.5 \mathrm{~g})$ of fructose added to white bread ('catalytic' fructose effect). Each study meal was designed to contain a total of $50 \mathrm{~g}$ of available carbohydrate with the exception of the study meals testing the 'catalytic' fructose effect. The'catalytic' dose of $7.5 \mathrm{~g}$ of fructose was derived from both free fructose and fructose bound in sucrose. The nutrient content of the study meals was analyzed by Merieux/ Silliker (Toronto, Canada) using the Association of Official Agricultural Chemists approved methods and is provided in Table 2.

\section{Blood sample collection and analysis}

Each finger-prick sample consisted of a total of 2-3 drops of capillary blood collected into flat-bottomed 5 $\mathrm{ml}$ plastic tubes with a push cap containing a small amount of sodium fluoride and potassium oxalate as an anticoagulant and preservative. The samples were mixed by rotating the tube vigorously and then refrigerated during the testing session. After completion of the test session, samples were stored at $-20^{\circ} \mathrm{C}$ prior to blood glucose analysis. Within five days of collection the blood glucose analysis was conducted using a YSI 
model 2300 STAT analyzer (Yellow Springs, OH) by a lab technician blinded to the treatment allocation.

\section{Primary outcome}

The primary outcome was GI, which was determined using the ISO method (ISO 26642:2010) and adjusted to the glucose scale, where GI of glucose $=100$ and white bread $=71$. Although the ISO method does not allow for mixed meals (displacement effect, 'catalytic' fructose effect) or meals containing $>50 \mathrm{~g}$ of available carbohydrate ('catalytic' fructose effect), we used this outcome measure for ease of comparison with the GI of dried fruit alone (GI effect).

The GI of the test meals was calculated by expressing each participant's incremental area under the blood glucose curve (iAUC) values for the test meal as a percentage of the same participant's mean iAUC for the three white bread control meals. The iAUC values were calculated using the trapezoidal rule, ignoring the area below fasting. For the purpose of the iAUC calculation, fasting glucose was taken to be the mean of the first measurement of the glucose concentration at times -5 and 0 min. GI values > 2 *standard deviation (SD) above the mean were excluded and replaced by the mean of the remaining values. GI and iAUC values were expressed as mean \pm SEM.

Using the $t$-distribution and assuming an average coefficient of variation $(\mathrm{CV})$ of within individual variation of iAUC values of $25 \%, n=10$ participants had $80 \%$ power to detect a $33 \%$ difference in iAUC with 2-tailed $P<0.05$.

\section{Statistical analysis}

Statistical analyses were conducted using SAS software (SAS Inst. Version 8.2; Gary, NC). Data were entered into a spreadsheet by two different individuals and the values compared to assure accurate transcription. Pairwise differences in GI and iAUC between the white bread control and the three mechanisms (GI effect; displacement effect; 'catalytic' fructose effect) for each of the 4 dried fruits (dates, apricots, raisins, sultanas) was assessed by the Dunnett's test, with $P<0.05$ considered statistically significant.

\section{Results}

A total of 10 participants ( 7 men; 3 women), with a mean \pm SD age and BMI of $39 \pm 12$ years and $25.3 \pm 2.3$ $\mathrm{kg} / \mathrm{m}^{2}$, respectively, were recruited and completed the study between November and December, 2016 (Fig. 1, Table 3).

\section{Within participant variation of reference food}

The mean within CV of the iAUC values after the 3 white bread control meals was $14.6 \%$, which is considered to be satisfactory (values $<30 \%$ are considered satisfactory (ISO 26642:2010)). 


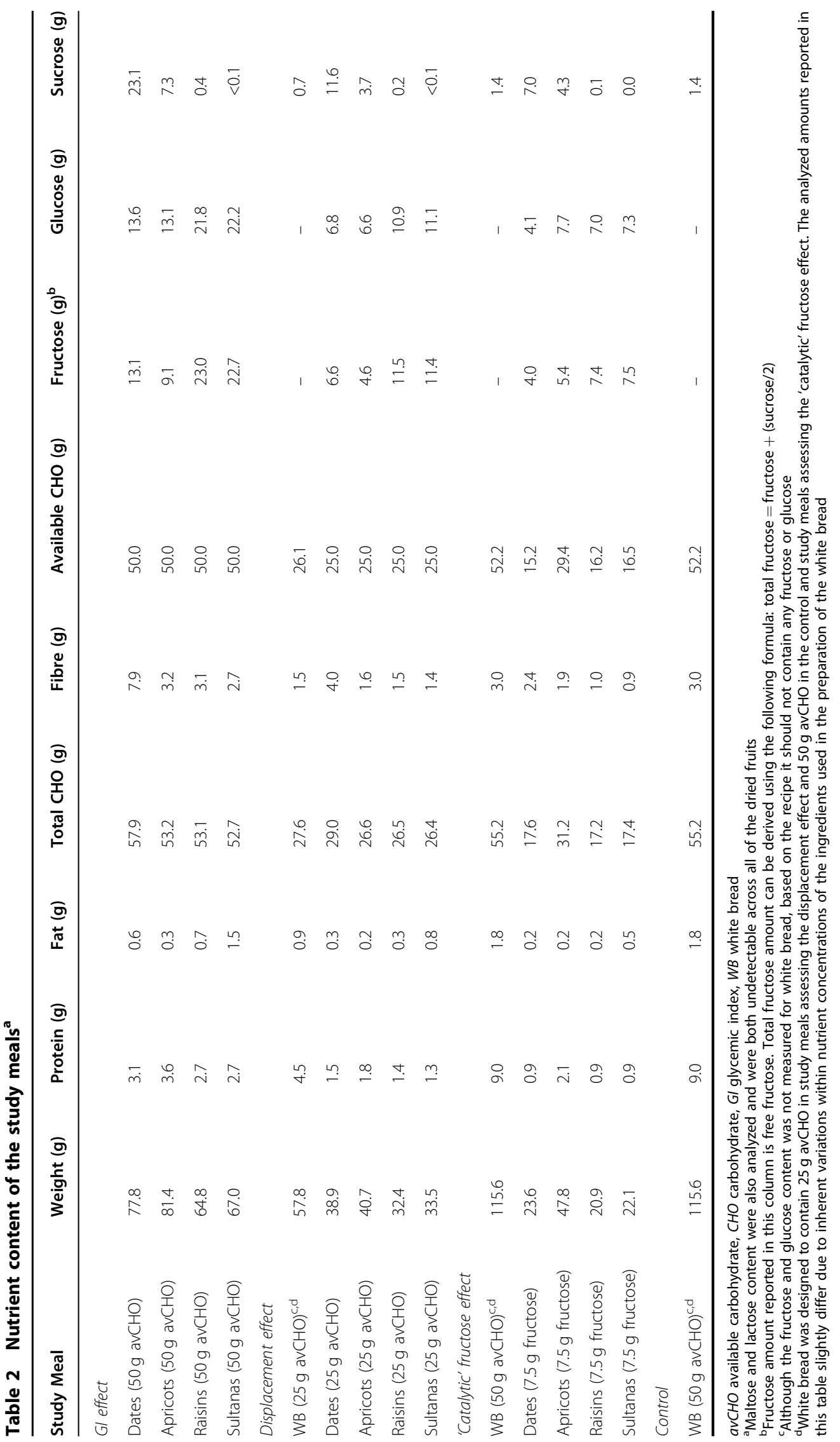




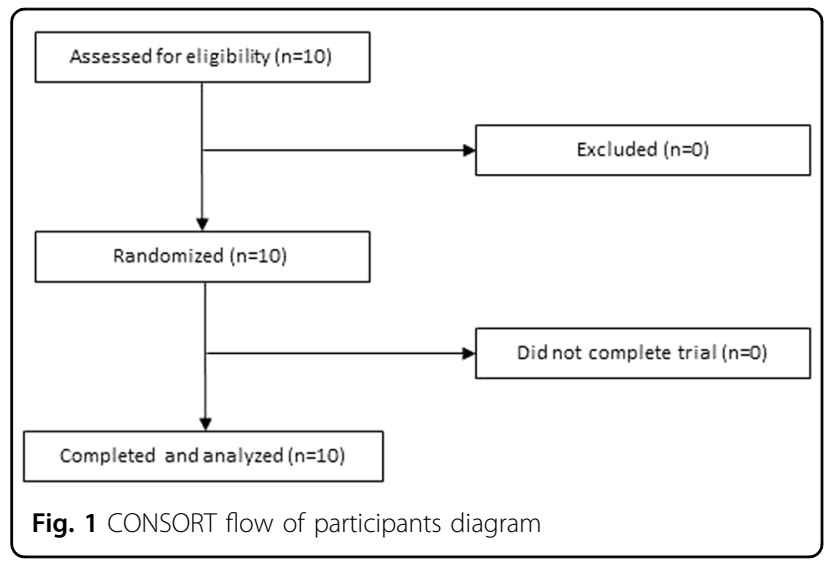

Postprandial glycemic responses and glycemic index

Table 4 shows the GI of the 4 dried fruits and their effects on postprandial glycemic responses through the three assessed mechanisms (GI effect; displacement effect; 'catalytic' fructose effect). All dried fruits lowered the postprandial glycemic response and had a GI below that of white bread; however, only the dried apricots (GI $=42$ $\pm 5)$, raisins $(\mathrm{GI}=55 \pm 5)$, and sultanas $(51 \pm 4)$ showed a significant GI effect $(P<0.05)$. When displacing half the available carbohydrate in white bread, all dried fruit lowered the postprandial glycemic response. However, only dried apricots $(\mathrm{GI}=57 \pm 5)$ significantly reduced the glycemic response through the displacement effect $(P=$ $0.025)$. None of the dried fruits showed a beneficial 'catalytic' fructose effect.

\section{Discussion}

The present study demonstrates that dried fruits (dates, apricots, raisins, and sultanas) have a low to medium GI. When displacing half of the available carbohydrate in white bread, all of the dried fruits lowered the GI, with dried apricots showing a significant displacement effect. None of the dried fruits showed a beneficial 'catalytic' fructose effect.

\section{Findings in relation to other studies and potential mechanisms}

Although there are a limited number of trials assessing the effect of dried fruits on cardiometabolic health outcomes, our findings are consistent with previous trials showing dried fruit to have a low to medium $\mathrm{GI}^{1-7}$ and to lower postprandial glycemia ${ }^{3,6-11}$. Several potential mechanisms may explain these findings. The low to medium GI and source of dietary fibre of dried fruits $(\sim 3-8 \mathrm{~g}$ of fibre per $1 / 4$ cup or $60 \mathrm{~mL}$, which is equivalent to one Canada Food Guide serving ${ }^{23}$ ) are factors that have both been shown to have benefits for glycemic control and diabetes risk reduction in randomized controlled trials ${ }^{24-27}$ and prospective cohort studies ${ }^{28-30}$.
Table 3 Participant characteristics

\begin{tabular}{ll}
\hline Characteristic & Mean \pm SD or No. \\
\hline$n$ & 10 \\
Age (years) & $39 \pm 12$ \\
Sex & \\
Men & 7 \\
Women & 3 \\
Race/Ethnicity & \\
Caucasian & 5 \\
Chinese & 1 \\
South East Asian & 1 \\
Black & 1 \\
Korean & 1 \\
Mixed & 1 \\
Weight $(\mathrm{kg})$ & $75.3 \pm 12.3$ \\
BMl (kg/m²) & $25.3 \pm 2.3$ \\
\hline
\end{tabular}

Their viscous fibre and whole food matrix are thought to be other contributors to lowering the glycemic response. Dried fruits are also a good source of phytochemicals (e.g., phenolic acids, flavonoids, carotenoids, etc.) $)^{31}$, which may play a role in modifying blood glucose and diabetes risk $^{32}$. Another potential mechanism may relate to the type of sugar present. Fructose, a low GI sugar, comprises $23-50 \%$ of the total sugar content of dried fruits $^{33,34}$. In systematic reviews and meta-analyses of controlled feeding trials, we demonstrated that small doses of fructose (defined as $\leq 36 \mathrm{~g} /$ day based on the following: 3 meals at $\leq 10 \mathrm{~g} / \mathrm{meal}$ and 2 snacks at $\leq 3 \mathrm{~g} /$ snack) ${ }^{35}$ and larger doses of fructose (median, $60 \mathrm{~g} /$ day $)^{36}$ in exchange for other carbohydrate sources decreased $\mathrm{HbA}_{1 \mathrm{c}}$ levels by 0.4 and $0.53 \%$, respectively. This level of reduction exceeds the clinically meaningful threshold of $0.3 \%$ proposed by the U.S. FDA for the development of new oral anti-hyperglycemic agents ${ }^{37}$. In terms of our findings regarding a displacement effect of dried fruit, we expect this would also be observed with other high GI carbohydrate foods. The addition of pistachios to a number of commonly consumed high GI carbohydrate foods (bread, pasta, rice, potato) was found to attenuate the glycemic response in healthy individuals $(n=10)$, all of which were statistically significant except for potato ${ }^{12}$. To our knowledge, only one randomized trial has been conducted where 4 different dried fruits (raisins, apples, jujubes, and apricots) were used to displace half the available carbohydrate of white rice in healthy individuals $(n=11)^{7}$. Similar to our findings, all 


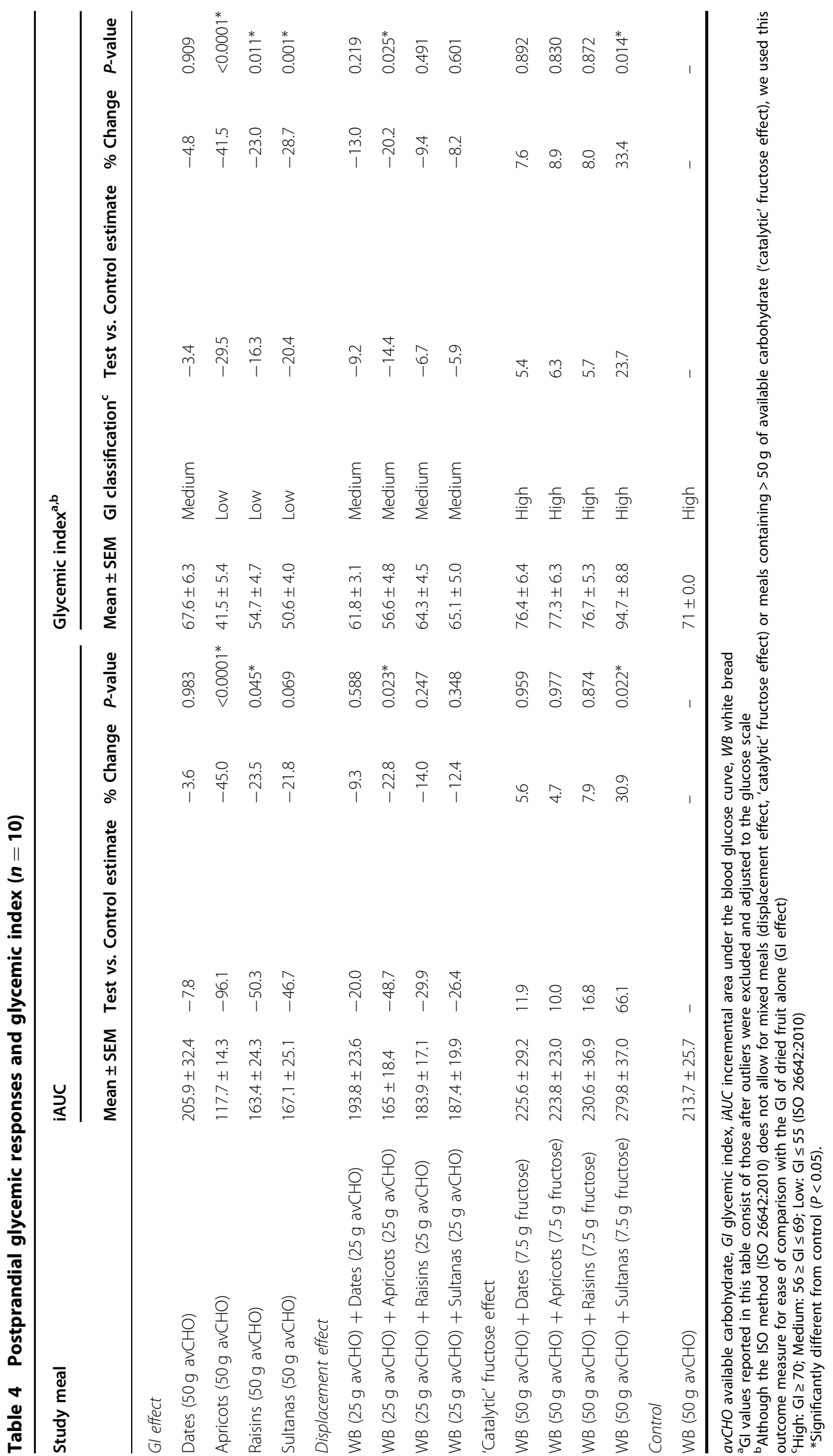


the dried fruits lowered the glycemic response relative to white rice alone, however, none were statistically significant due to high variability ${ }^{7}$. It would appear that a larger number of participants would be required to consistently observe a significant displacement effect with dried fruit.

\section{Limitations}

This study has several limitations. First, the results of this acute feeding trial cannot be translated into long-term benefits. Second, the small sample size of 10 participants, although validated, makes these findings less precise and generalizable. Third, the ISO method for determining GI was not followed for the study meals assessing the displacement and 'catalytic' fructose effect mechanisms as they consisted of a mixed meal and/or $>50 \mathrm{~g}$ of available carbohydrate. The purpose of determining the GI for study meals assessing these two mechanisms was for ease of comparisons with the GI of dried fruit alone (GI effect) and can be regarded as a relative glycemic response. Fourth, an imbalance in available carbohydrate in assessing the 'catalytic' fructose effect may have confounded the results. Because the test meals assessing the 'catalytic' fructose effect used 'real world' whole food sources of fructose from dried fruit rather than fructose alone, there was additional glucose and sucrose contained in these meals. The additional glucose and sucrose would have increased the relative amount of available glycemic carbohydrate (free glucose or glucose from the hydrolysis of sucrose and starch) in the dried fruit test meal compared with that in the white bread control meal (starch alone), resulting in a higher glycemic response, which may have offset any 'catalytic' effect of fructose. Future trials should consider standardizing the amount of available glycemic carbohydrate in study meals that assess the effect of 'catalytic' doses of fructose from whole foods.

\section{Implications}

Our study aimed to assess the effect of the most commonly consumed dried fruits. According to estimates from the International Nut and Dried Fruit Foundation, dried grapes (including raisins and sultanas), followed by dates, were the most highly consumed dried fruits in both high- and middle-income countries ${ }^{38}$. Estimates were also provided for dried apricots, prunes, and dried figs, which were consumed at lower levels relative to dried grapes and dates ${ }^{38}$. Dried fruits, which can be processed using various drying methods to extend their shelf life as dried fruits, are nutritionally equivalent to fresh fruits in smaller serving sizes ${ }^{31}$. This property makes dried fruit easier to store and distribute throughout the year and provides a healthier alternative to high GI food products $^{31}$. Given that a small percentage of the U.S. population consumes dried fruits (7\%) (41) and the observed benefits of dried fruits on postprandial glycemic response levels, there is opportunity to use them in combination with high GI foods to lower their GI and help with blood glucose management. Although we predict that the use of other dried fruits to displace available carbohydrate from other high GI foods will produce similar findings to ours, more randomized trials are needed in this area to confirm this.

\section{Conclusions}

The results of this study show that dried fruit have a lower GI than white bread and can lower the glycemic response of white bread through displacement of half of the available carbohydrate. Longer and larger randomized trials are needed to confirm whether dried fruit can contribute to sustainable improvements in glycemic control, as well as assess whether other types of dried fruits and displacement of available carbohydrate from other high GI foods will show similar findings. Overall, these findings will help stimulate important industry innovation and improve the design of future clinical investigations that will potentially lead to the use of dried fruits as an effective tool to modify the glycemic response of high carbohydrate foods.

\section{Acknowledgements}

This work was supported by the International Nut and Dried Fruit Council Foundation and the National Dried Fruit Trade Association. All study foods were provided by the National Dried Fruit Trade Association. Effie Viguiliouk was supported by a Toronto 3D Knowledge Synthesis and Clinical Trials foundation Internship Award. John L Sievenpiper was funded by a PSI Graham Farquharson Knowledge Translation Fellowship, Canadian Diabetes Association Clinician Scientist award, CIHR INMD/CNS New Investigator Partnership Prize, and Banting \& Best Diabetes Centre Sun Life Financial New Investigator Award. None of the sponsors had a role in any aspect of the present study, including design and conduct of the study; collection, management, analysis, and interpretation of the data; and preparation, review, approval of the manuscript or decision to publish.

\section{Authors' contributions}

J.L.S. and C.W.C.K. conceived and designed the study and oversaw the running of the clinical trial; E.V. and A.L.J. were responsible for the day to day running of the study and analyzed the data; all authors contributed to the interpretation of the data and the content of the manuscript.

\section{Author details \\ ${ }^{1}$ Toronto 3D Knowledge Synthesis and Clinical Trials Unit, St. Michael's Hospital, Toronto, Canada. ${ }^{2}$ Department of Nutritional Sciences, Faculty of Medicine, University of Toronto, Toronto, Canada. ${ }^{3}$ Glycemic Index Laboratories, Toronto, Canada. ${ }^{4}$ Division of Endocrinology \& Metabolism, St. Michael's Hospital, Toronto, Canada. ${ }^{5}$ Li Ka Shing Knowledge Institute, St. Michael's Hospital, Toronto, Canada. ${ }^{6} \mathrm{College}$ of Pharmacy and Nutrition, University of Saskatchewan, Saskatoon, Canada}

\section{Conflict of interest}

A.L.J. is a part owner of Glycemic Index Laboratories. J.L.S. has received research support from the Canadian Institutes of health Research (CIHR), Diabetes Canada, PSI Foundation, Banting and Best Diabetes Centre (BBDC), Canadian Nutrition Society (CNS), American Society for Nutrition (ASN), INC International Nut and Dried Fruit Council Foundation, National Dried Fruit Trade Association, The Tate and Lyle Nutritional Research Fund at the University of Toronto, The Glycemic Control and Cardiovascular Disease in Type 2 Diabetes Fund at the University of Toronto (a fund established by the 
Alberta Pulse Growers), and the Nutrition Trialists Fund at the University of Toronto (a fund established by the Calorie Control Council). He has received food donations to support randomized controlled trials from the Almond Board of California, California Walnut Commission, American Peanut Council, Barilla, Unilever, Unico/Primo, Loblaw Companies, Quaker (Pepsico), Kellogg Canada, and WhiteWave Foods. He has received travel support, speaker fees and/or honoraria from Diabetes Canada, Canadian Nutrition Society (CNS), Mott's LLP, Dairy Farmers of Canada, Alberta Milk, FoodMinds LLC, Memac Ogilvy \& Mather LLC, PepsiCo, The Ginger Network LLC, International Sweeteners Association, Nestlé, Pulse Canada, Canadian Society for Endocrinology and Metabolism (CSEM), Gl Foundation, Barilla Centre for Food and Nutrition (BCFN), Abbott, Biofortis, California Walnut Commission, American Society for Nutrition (ASN), Loma Linda University, Dietitians of Canada, European Food Safety Authority, and Physicians Committee for Responsible Medicine. He has or has had ad hoc consulting arrangements with Winston \& Strawn LLP, Perkins Coie LLP, Tate \& Lyle, and Wirtschaftliche Vereinigung Zucker e.V. He is a member of the European Fruit Juice Association Scientific Expert Panel. He is on the Clinical Practice Guidelines Expert Committees of Diabetes Canada, European Association for the study of Diabetes (EASD), Canadian Cardiovascular Society (CCS), and Obesity Canada. He serves as an unpaid scientific advisor for the Food, Nutrition, and Safety Program (FNSP) and the Technical Committee on Carbohydrates of the International Life Science Institute (ILSI) North America. He is a member of the International Carbohydrate Quality Consortium (ICQC), Executive Board Member of the Diabetes and Nutrition Study Group (DNSG) of the EASD, and Director of the Toronto 3D Knowledge Synthesis and Clinical Trials foundation. His wife is an employee of Unilever Canada.. C.W.C.K. has received grant grants or research support from the Advanced Food Materials Network, Agriculture and Agri-Foods Canada (AAFC), Almond Board of California, American Pistachio Growers, Barilla, Calorie Control Council, Canadian Institutes of Health Research (CIHR), Canola Council of Canada, International Nut and Dried Fruit Council, International Tree Nut Council Research and Education Foundation, Loblaw Brands Ltd, Pulse Canada, Saskatchewan Pulse Growers and Unilever. He has received in-kind research support from the Almond Board of California, American Peanut Council, Barilla, California Walnut Commission, Kellogg Canada, Loblaw Companies, Quaker (Pepsico), Primo, Unico, Unilever, WhiteWave Foods. He has received travel support and/or honoraria from the American Peanut Council, American Pistachio Growers, Barilla, California Walnut Commission, Canola Council of Canada, General Mills, International Nut and Dried Fruit Council, International Pasta Organization, Loblaw Brands Ltd, Nutrition Foundation of Italy, Oldways Preservation Trust, Paramount Farms, Peanut Institute, Pulse Canada, Sabra Dipping Co., Saskatchewan Pulse Growers, Sun-Maid, Tate \& Lyle, Unilever and White Wave Foods. He has served on the scientific advisory board for the International Tree Nut Council, International Pasta Organization, McCormick Science Institute, Oldways Preservation Trust, Paramount Farms and Pulse Canada. He is a member of the International Carbohydrate Quality Consortium (ICQC), Executive Board Member of the Diabetes and Nutrition Study Group (DNSG) of the European Association for the Study of Diabetes (EASD), is on the Clinical Practice Guidelines Expert Committee for Nutrition Therapy of the EASD and is a Director of the Toronto 3D Knowledge Synthesis and Clinical Trials foundation. No competing interests were declared by Effie Viguiliouk and Sonia Blanco Mejia. The remaining authors declare that they have no conflict of interest.

\section{Publisher's note}

Springer Nature remains neutral with regard to jurisdictional claims in published maps and institutional affiliations.

Received: 15 February 2018 Revised: 28 August 2018 Accepted: 13 October 2018

Published online: 11 December 2018

\section{References}

1. Jenkins, D. J. et al. Glycemic index of foods: a physiological basis for carbohydrate exchange. Am. J. Clin. Nutr. 34, 362-366 (1981).
2. Kim, Y., Hertzler, S. R., Byrne, H. K. \& Mattern, C. O. Raisins are a low to moderate glycemic index food with a correspondingly low insulin index. Nutr. Res. 28 304-308 (2008).

3. Esfahani, A., Lam, J. \& Kendall, C. W. Acute effects of raisin consumption on glucose and insulin reponses in healthy individuals. J. Nutr. Sci. 3, e1 (2014).

4. Alkaabi, J. M. et al. Glycemic indices of five varieties of dates in healthy and diabetic subjects. Nutr. J. 10, 59 (2011).

5. Miller, J. B., Pang, E. \& Broomhead, L. The glycaemic index of foods containing sugars: comparison of foods with naturally-occurring v. added sugars. Br. J. Nutr. 73, 613-623 (1995).

6. Kanellos, P. T. et al. A study of glycemic response to Corinthian raisins in healthy subjects and in type 2 diabetes mellitus patients. Plant Foods Hum. Nutr. 68, 145-148 (2013)

7. Zhu, R., et al. Postprandial glycaemic responses of dried fruit-containing meals in healthy adults: results from a randomised trial. Nutrients. 10, pii: E694 (2018).

8. Anderson, J. W., Weiter, K. M., Christian, A. L., Ritchey, M. B. \& Bays, H. E. Raisins compared with other snack effects on glycemia and blood pressure: a randomized, controlled trial. Postgrad. Med. 126, 37-43 (2014).

9. Bays, H., Weiter, K. \& Anderson, J. A randomized study of raisins versus alternative snacks on glycemic control and other cardiovascular risk factors in patients with type 2 diabetes mellitus. Phys. Sportsmed. 43, 37-43 (2015).

10. Famuyiwa, O. O. et al. A comparison of acute glycemic and insulin-response to dates (Phoenix-Dactylifera) and oral dextrose in diabetic and nondiabetic subjects. Saudi. Med. J. 13, 397-402 (1992).

11. Ahmed, M., Al-Othaimeen, A., De Vol, E. \& Bold, A. Comparative responses of plasma glucose, insulin and C-peptide following ingestion of isocaloric glucose, a modified urban Saudi breakfast and dates in normal Saudi persons. Ann. Saudi. Med. 11, 414-417 (1991).

12. Kendall, C. W., Josse, A. R., Esfahani, A. \& Jenkins, D. J. The impact of pistachio intake alone or in combination with high-carbohydrate foods on postprandial glycemia. Eur. J. Clin. Nutr. 65, 696-702 (2011).

13. Josse, A. R., Kendall, C. W., Augustin, L. S., Ellis, P. R. \& Jenkins, D. J. Almonds and postprandial glycemia-a dose-response study. Metabolism 56, 400-404 (2007).

14. Agius, L. \& Peak, M. Intracellular binding of glucokinase in hepatocytes and translocation by glucose, fructose and insulin. Biochem. J. 296(Pt 3), 785-796 (1993).

15. Van Schaftingen, E., Detheux, M., Veiga \& da Cunha, M. Short-term control of glucokinase activity: role of a regulatory protein. FASEB J. 8, 414-419 (1994).

16. Detheux, M., Vandercammen, A. \& Van Schaftingen, E. Effectors of the regulatory protein acting on liver glucokinase: a kinetic investigation. Eur. J. Biochem. 200, 553-561 (1991).

17. Vandercammen, A., Detheux, M. \& Van Schaftingen, E. Binding of sorbitol 6phosphate and of fructose 1-phosphate to the regulatory protein of liver glucokinase. Biochem. J. 286(Pt 1), 253-256 (1992).

18. Petersen, K. F., Laurent, D., Yu, C., Cline, G. W. \& Shulman, G. I. Stimulating effects of low-dose fructose on insulin-stimulated hepatic glycogen synthesis in humans. Diabetes 50, 1263-1268 (2001).

19. Hawkins, M. et al. Fructose improves the ability of hyperglycemia per se to regulate glucose production in type 2 diabetes. Diabetes 51, 606-614 (2002).

20. Moore, M. C., Cherrington, A. D., Mann, S. L. \& Davis, S. N. Acute fructose administration decreases the glycemic response to an oral glucose tolerance test in normal adults. J. Clin. Endocrinol. Metab. 85, 4515-4519 (2000).

21. Heacock, P. M., Hertzler, S. R. \& Wolf, B. W. Fructose prefeeding reduces the glycemic response to a high-glycemic index, starchy food in humans. J. Nutr. 132, 2601-2604 (2002).

22. Moore, M. C., Davis, S. N., Mann, S. L. \& Cherrington, A. D. Acute fructose administration improves oral glucose tolerance in adults with type 2 diabetes. Diabetes Care 24, 1882-1887 (2001).

23. Health Canada (2011). Eating Well With Canada's Food Guide. http://www.hcsc.gc.ca/fn-an/food-guide-aliment/index-eng.php. Accessed 30 October 2018.

24. Ajala, O., English, P. \& Pinkney, J. Systematic review and meta-analysis of different dietary approaches to the management of type 2 diabetes. Am. J. Clin. Nutr. 97, 505-516 (2013).

25. Wang, Q., Xia., W., Zhao, Z. \& Zhang, H. Effects comparison between low glycemic index diets and high glycemic index diets on $\mathrm{HbA1c}$ and fructosamine for patients with diabetes: a systematic review and meta-analysis. Prim Care. Diabetes 9, 362-369 (2015). 
26. Silva, F. M. et al. Fiber intake and glycemic control in patients with type 2 diabetes mellitus: a systematic review with meta-analysis of randomized controlled trials. Nutr. Rev. 71, 790-801 (2013).

27. Chandalia, M. et al. Beneficial effects of high dietary fiber intake in patients with type 2 diabetes mellitus. N. Engl. J. Med. 342, 1392-1398 (2000).

28. Bhupathiraju, S. N. et al. Glycemic index, glycemic load, and risk of type 2 diabetes: results from 3 large US cohorts and an updated meta-analysis. Am. J. Clin. Nutr. 100, 218-232 (2014).

29. Greenwood, D. C. et al. Glycemic index, glycemic load, carbohydrates, and type 2 diabetes: systematic review and dose-response metaanalysis of prospective studies. Diabetes Care 36, 4166-4171 (2013).

30. erAct, C. Dietary fibre and incidence of type 2 diabetes in eight European countries: the EPIC-InterAct Study and a meta-analysis of prospective studies. Diabetologia 58, 1394-1408 (2015). Int.

31. SKAC, Chang. \& Shahidi, F. Review of dried fruits: phytochemicals, antioxidant efficacies, and health benefits. J. Funct. Foods 21, 113-132 (2016).

32. Kim, Y., Keogh, J. B., Clifton, P. M. Polyphenols and glycemic control. Nutrients. 8, pii: E17 (2016)
33. USDA (2016). USDA National Nutrient Database for Standard Reference. http:// www.ars.usda.gov/ba/bhnrc/ndl. Accessed 30 October 2018.

34. Hernandez-Alonso, P., Camacho-Barcia, L., Bullo, M., Salas-Salvado, J. Nuts and dried fruits: an update of their beneficial effects on type 2 diabetes. Nutrients. 9, pii: E673 (2017)

35. Sievenpiper, J. L. C. L. et al. 'Catalytic' doses of fructose may benefit glycaemic control without harming cardiometabolic risk factors: a small meta-analysis of randomised controlled feeding trials. Br. J. Nutr. 108, 418-423 (2012).

36. Cozma, A. I. et al. Effect of fructose on glycemic control in diabetes: a systematic review and meta-analysis of controlled feeding trials. Diabetes Care 35 1611-1620 (2012).

37. Center for Drug Evaluation and Research (CDER). Guidance for Industry Diabetes Mellitus: Developing Drugs and Therapeutic Biologics for Treatment and Prevention (DRAFT GUIDANCE). 1-30 (U.S Department of Health and Human Services, Food and Drug Administration, Rockville, MD, 2008).

38. International Nut and Dried Fruit Foundation (2017). Nuts and Dried Fruits Statistical Yearbook 2017/2018. https://www.nutfruit.org/industry/technicalresources?category=statistical-yearbooks.. Accessed 30 October 2018. 